\title{
An MCDA approach for evaluating hydrogen storage systems for future vehicles
}

\author{
Florent MONTIGNAC \\ CEA, LITEN, 17 rue des Martyrs, 38054 Grenoble Cedex 9
}

Vincent MOUSSEAU,

LGI, Ecole Centrale Paris, Grande voie des Vignes, 92295 Châtenay-Malabry

Denis BOUYSSOU, Mohamed Ali ALOULOU, Benjamin ROUSVAL

LAMSADE, UMR 7024, Université Paris Dauphine, Place du Maréchal de Lattre de

Tassigny, 75775 Paris Cedex 16

Sébastien DAMART

DRM M-Lab, Université Paris Dauphine, Place du Maréchal de Lattre de Tassigny, 75775 Paris Cedex 16

\begin{abstract}
Hydrogen, a non carbonated energy carrier, is often considered as one possible solution to reduce greenhouse gas emissions from human activity. The use of hydrogen as a possible alternative fuel for automotive applications is envisaged by car manufacturers. However, before a large scale commercialization of hydrogen vehicles, numerous challenges have to be faced, among which the on-board storage of hydrogen. This paper provides a description of the implementation of an MCDA approach for evaluating various competing hydrogen storage technologies for future vehicles. This implementation has been conducted within the STORHY European research project. The MACBETH method has been identified as an appropriate approach for the evaluation and comparison of the technologies from a technical point of view. The evaluation process has been entirely implemented on one hand close to several experts from CEA and on the other hand close to one of the STORHY car manufacturers. The implementation within the project confirmed that this evaluation method could be used for "application-oriented" multicriteria evaluations. The advantages and drawbacks of the method are finally discussed.
\end{abstract}

\section{Keywords}

Automotive applications, hydrogen storage, evaluation, MACBETH

\section{Introduction}

The intensive worldwide use of carbonated fossil fuels (oil, natural gas, coal) in human activities since the early twentieth century led to a remarkable increase of the $\mathrm{CO}_{2}$ atmospheric concentration. This strong increase of the greenhouse gases emissions is considered to be responsible for the climate change phenomenon we are facing with [1]. In order to limit the intensity of this phenomenon and to protect the environment, the urgent development of new $\mathrm{CO}_{2}$-free energy technologies is required. 
Hydrogen energy is one possible alternative to the use of carbonated fossil fuels ([2] to [6]). Hydrogen gas can be produced from various $\mathrm{CO}_{2}$-free primary energy sources such as solar, wind or nuclear energies. It can be potentially used as a transportation fuel in hydrogen fuel cell cars; it can also be converted in fuel cell stationary systems for residential and industrial heat and electricity generation.

Today transportation sector is the subject of intensive contribution to the $\mathrm{CO}_{2}$ emissions from human activity and the implementation of hydrogen as a transportation fuel is the object of intensive research and development activities. One of the most crucial research topics in the field of automotive applications is the storage of hydrogen [7].

In ambient conditions, hydrogen, as a gas, is characterized by a particularly low volumetric energy density in comparison with conventional liquid carbonated fossil fuels such as gasoline. In order to increase the volumetric energy density, various hydrogen storage technologies are being investigated by car manufacturers: compressed gaseous hydrogen storage, liquid hydrogen storage and solid storage of hydrogen. Today, none of these three alternatives totally fulfils all the requirements specified by car manufacturers and a strong need of evaluation and comparison of the performance and potential of these technologies is expressed by stakeholders in the field of hydrogen technologies.

Within this study, the three main hydrogen storage technologies (compressed, liquid and solid) were evaluated and compared using an MCDA approach. This study was achieved within the European research project "STORHY" (Hydrogen Storage Systems for Automotive Application). The general objectives of this project are presented in section 2. The reasons for choosing MACBETH evaluation method for evaluating and comparing the technical performance of hydrogen storage systems are reported in section 3. The implementation of the method within the project is then discussed. Finally in section 4 some comments on this case study and on the decision aiding process are formulated.

\section{General framework of the study: the STORHY European Project}

\subsection{The STORHY European Project}

The study described in this article has been conducted within the European research project "STORHY" (Hydrogen Storage Systems for Automotive Application). This project was an Integrated Project (IP) of the sixth Framework Programme involving thirty-four partners (private companies, public research centres and universities) from 13 European countries. It began in March 2004 and ended in August 2008. The central objective of the project was to develop hydrogen storage technologies for automotive application, focusing on (i) $70 \mathrm{MPa}$ compressed hydrogen storage systems, (ii) lightweight liquid hydrogen storage systems and (iii) improved lightweight materials for solid storage of hydrogen. Complementary to these technological objectives, an evaluation of the performance and safety of these systems has been planned [8]. Thus, the STORHY integrated project has been organized in six subprojects (Figure 1):

- three of the six subprojects (SP) dedicated to the technical development of hydrogen storage systems

○ SP Pressure: development of new $70 \mathrm{MPa}$ compressed hydrogen storage systems

- SP Cryogenic: development of new lightweight liquid hydrogen storage systems

- SP Solid: development of improved lightweight materials for solid storage of hydrogen 
- three subprojects dedicated to transversal activities

- SP Users: car manufacturers' requirements

- SP Safety: evaluation of the safety of the hydrogen storage systems

- SP Evaluation: multicriteria evaluation of the hydrogen storage systems

The study described in this article has been conducted within subproject Evaluation. The objectives of this subproject are presented in the following subsection.

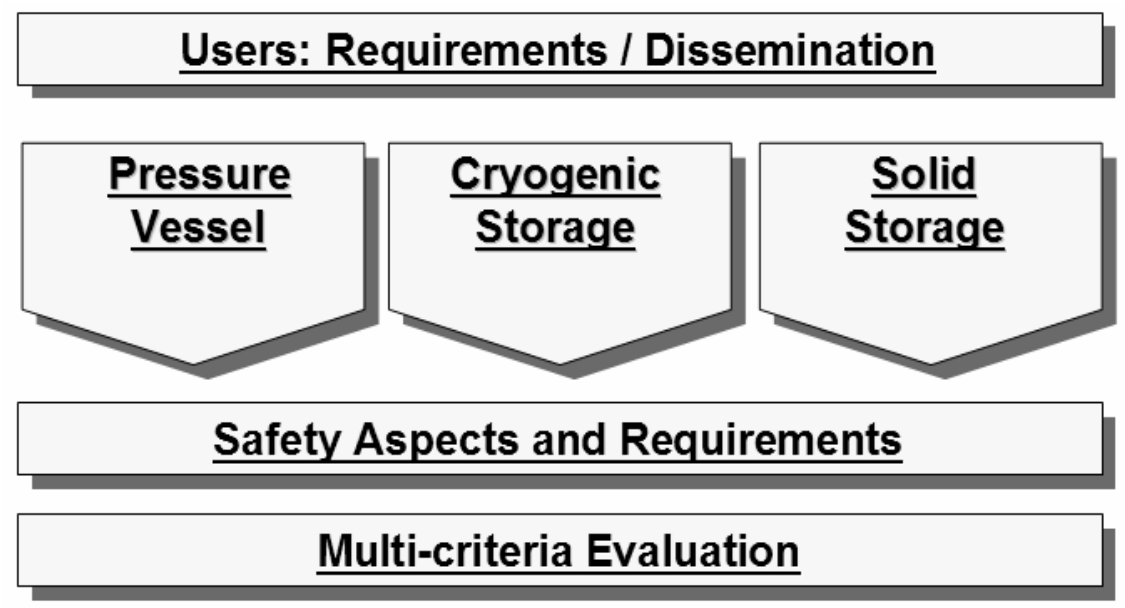

Figure 1: Structure of the STORHY integrated project [8].

\subsection{The subproject Evaluation}

Why a "subproject Evaluation"?

The reason for involving a subproject dedicated to the multicriteria evaluation was the following: the European Commission asked for an evaluation and comparison of the performance of the hydrogen storage technologies developed within the STORHY project so that the results of such an evaluation could orientate the further financial support towards the remaining technological hurdles before commercialization. The client of the study conducted by the subproject Evaluation was then the European Commission. Using the MCDA terminology, the European Commission was the "client" of the study while the subproject Evaluation was the "analyst" [9].

Formally, the CEA was responsible for the SP evaluation. As the CEA did not have particular expertise in the field of multicriteria evaluation, a team from LAMSADE was hired to assist CEA in the conduct of this SP. This team therefore acted as the "analyst of the analyst". It had no direct access to the various stakeholders of the project. The LAMSADE team worked together with CEA on the SP evaluation for approximately twelve months. As this will be described in 3.3.1, the implementation of the MACBETH multicriteria evaluation method has been conducted by the LAMSADE team on one hand close to experts from CEA, and on the other hand close to one STORHY car manufacturer.

\section{What was the scope of the evaluation?}

The aim of the subproject Evaluation was to provide an argued evaluation and comparison of the performance reached by the hydrogen storage technologies developed within the STORHY project. At the time the STORHY project was negociated, it was decided to take five "evaluation domains" into account (Figure 2): 
- technical performance,

- environmental impacts,

- costs,

- safety,

- social acceptance.

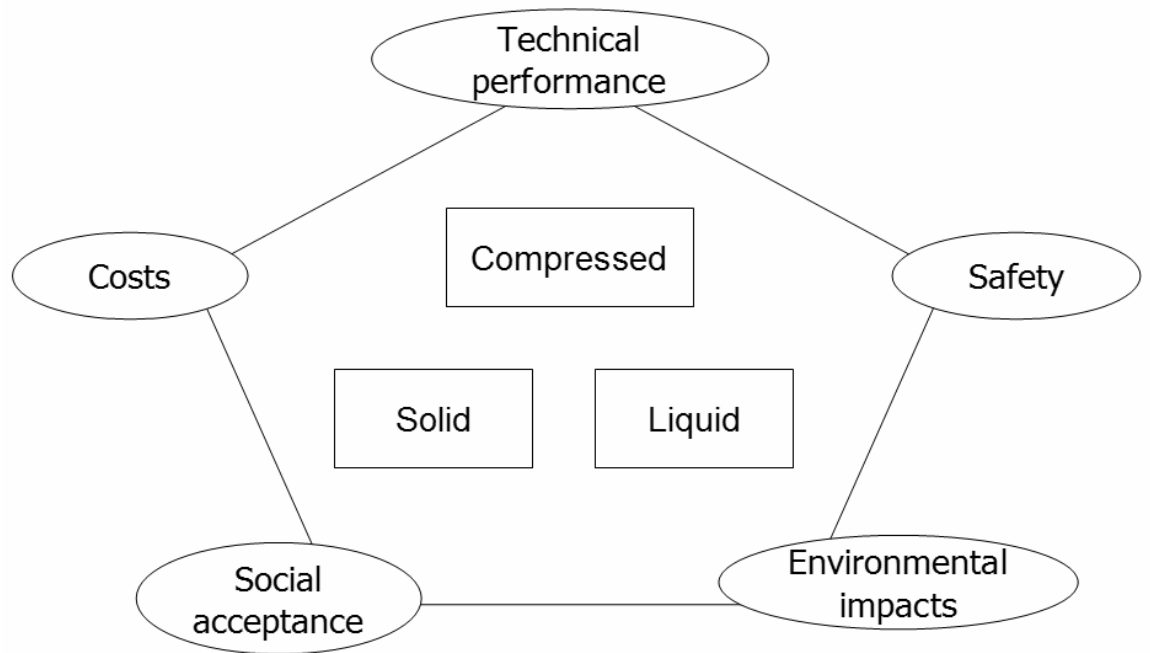

Figure 2: Five evaluation domains have been taken into account by the subproject Evaluation for the evaluation and comparison of the hydrogen storage technologies.

Who were the decision makers or stakeholders?

Within the STORHY project, no decision maker could be identified. The specificity of the evaluation context was that the car manufacturers (identified as the stakeholders) did not share a unique consensual vision of the requirements for hydrogen storage technologies. Car manufacturers were involved in the whole evaluation process in order to define appropriate evaluation criteria, appropriate final automotive applications and relevant performance targets for hydrogen storage systems. In such a context, the role of the analyst was not to conduct a "decision-aiding process" but rather an "evaluation-aiding process" aiming at providing objective elements of evaluation and comparison. Needless to say that behind STORHY there were huge industrial and commercial stakes. Although car manufacturers were involved in the project, they were comprehensibly reluctant, to openly share information with other members of the project. This explains why the delicate question of managing the multi-actor aspects involved in the SP evaluation could not be explicitly dealt with, within the period in which LAMSADE and CEA collaborated on the project.

What was the role of the other SP?

In addition to the state-of-the-art data found in the literature, the collection of data was carried out close to experts from CEA, the STORHY technical subprojects dedicated to the development of the hydrogen storage technologies (subprojects Pressure, Cryogenic and Solid) and to the study of safety aspects (subproject Safety).

\section{Summary}

Thus, to sum-up using the MCDA terminology, the actors involved in the overall evaluation process were the following (Figure 3):

- the client was the European Commission,

- the stakeholders were the STORHY car manufacturers (subproject Users), 
- the analyst of the project was the subproject Evaluation,

- the experts were the technical subprojects developing the hydrogen storage technologies and providing raw data.

STORHY project



Figure 3: Overview of the actors involved in the multicriteria evaluation study, using the MCDA terminology.

\subsection{Focus on the evaluation of the technical performance}

As a result of an early discussion in the project between the analyst (subproject Evaluation) and the stakeholders (subproject Users), it has been decided to emphasize the study on the technical performance of the hydrogen storage systems. The reason for this choice was that the assessment of the "technological feasibility" for hydrogen storage was considered by the stakeholders to be a priority before any other kind of evaluation. Thus, even if all of the evaluation domains specified in Figure 2 have been explored by the SP Evaluation during the STORHY project, the method and results provided in the following sections of this article are focusing especially on the technical performance evaluation domain. Moreover the technical evaluation domain was identified by the LAMSADE and the CEA as an appropriate evaluation domain for the "pilot" implementation of a multicriteria evaluation method provided that this was the most studied evaluation domain among the five envisaged.

In order to model and compare the technical performance of the assessed hydrogen storage technologies (pressure, liquid and solid), a set of five technical evaluation criteria has been defined at the beginning of the project:

- System volume (litres): volume of the whole hydrogen storage system included in the vehicle.

- System mass (kilograms): mass of the whole hydrogen storage system included in the vehicle.

- Refuelling time (minutes): time spent by an end-user at the refuelling station for a complete filling of the empty hydrogen storage system.

- Hydrogen loss rate (gram per hour per kilogram of hydrogen): amount of hydrogen lost by a filled hydrogen storage system while the vehicle is not used by the end-user.

- Conformability (qualitative criterion): ability of the hydrogen storage system to be shaped in various geometries so that it could be included in existing vehicle architecture.

These criteria, defined in cooperation between the SP Evaluation and the stakeholders, were quantified for various final automotive applications. In this study, we have decided to focus 
on a particular type of application, that of a "private fuel cell vehicle application, with a range of $600 \mathrm{~km}$, that is to say a storage capacity of $6 \mathrm{~kg}$ of hydrogen on-board". This means that the evaluation and comparison between the three hydrogen storage technologies (pressure, liquid and solid) has been conducted taking into account a storage capacity of $6 \mathrm{~kg}$ of hydrogen.

The next section 3 explains why MACBETH method has been identified as an appropriate approach for the modelling and evaluation of these criteria in the context of the STORHY project and provides an overview of the implementation process of this method.

\section{MACBETH: motivation and brief description}

\subsection{The choice of MACBETH}

As it has been presented in the previous section 2, focus has been made on five evaluation criteria: system volume (litres), system mass $(\mathrm{kg})$, refuelling time $(\mathrm{min})$, hydrogen loss rate ( $\mathrm{g} / \mathrm{h} / \mathrm{kg}_{\mathrm{H} 2}$ ) and conformability (qualitative criterion). Three technologies had to be compared (pressure, liquid and solid). The final automotive application that has been chosen for this comparison was a "private fuel cell vehicle application, with a range of $600 \mathrm{~km}$, that is to say a storage capacity of $6 \mathrm{~kg}$ of hydrogen on-board”.

Due to the R\&D context of this multicriteria evaluation, the requirements regarding the evaluation method were the following:

- to provide a relative comparison of the performances of the pressure, liquid and solid storage technologies (ranking and gaps of performance between the technologies),

- to provide an absolute assessment of these performances regarding the technical objectives of the car manufacturers (quantified targets),

- to model the notion of "remaining R\&D needs",

- to model and process both quantitative (system volume, system mass, hydrogen loss rate, refuelling time) and qualitative (conformability) criteria,

- to provide comparable individual formal outputs in situation with multiple stakeholders.

In that case, MACBETH ${ }^{1}$ method has been identified as an appropriate method for the evaluation:

- this method fulfils the requirements previously listed,

- the method can be easily implemented thanks to a user-friendly interface (the MMACBETH software),

- several evaluation models can be built close to different stakeholders,

- the questioning procedure in MACBETH is appropriate for taking into account the uncertainties of the raw performance data.

The LAMSADE team considered to use a more ordinal evaluation technique such as ELECTRE TRI [10]. However, it was felt that the people working in the other SP would not accept to work with an evaluation method that would not apparently take explicit advantage of the considerable data gathering that they were making. Hence, the choice of a more

\footnotetext{
1 "Measuring Attractiveness by a Categorical Based Evaluation TecHnique" ([11] to [14]).
} 
"cardinal" approach, such as MACBETH. The principles of this method are provided in the next subsection.

\subsection{General principles of MACBETH method}

The MACBETH method ([11] to [14]) relies on a cardinal multicriteria aggregation procedure. Its specificity is that it requires only qualitative judgements about differences of attractiveness of value to help an individual or a group quantify the relative attractiveness of options. At first its aim is to translate the performances $g_{i}(a)$ of the alternative $a$ regarding each criterion $g_{i}$ into a new performance $v_{i}\left(g_{i}(a)\right)$ representing the attractiveness of the alternative $a$ on a normalized scale. Secondly "scaling constants" (weights) $w_{i}$ are determined for each evaluation criterion in order to proceed to a weighted sum of the normalized scales. In other words, considering $n$ evaluation criteria, the performance $v(a)$ of an alternative $a$ can be modelled as:

$v(a)=\sum_{i=1}^{n} w_{i} v_{i}\left(g_{i}(a)\right)$

The implementation of MACBETH method is done interviewing a stakeholder and determining with him/her scales of attractiveness $v_{i}$ and scaling constants $w_{i}$. In the example of the evaluation of hydrogen storage technologies for automotive applications, the interviewed stakeholders were experts from CEA and car manufacturers. The next subsections describe how MACBETH method was implemented in the specific case of the evaluation of hydrogen storage technologies for automotive applications, in the frame of the STORHY European project.

3.3 Implementation of the MACBETH method for the evaluation and comparison of the technical performance of hydrogen storage systems

\subsubsection{Who has been interviewed?}

Within the project, the implementation of MACBETH method for the technical evaluation and comparison of the hydrogen storage technologies has been conducted with the following approach:

- internal implementation made by the analyst himself (in order to ensure that the MACBETH method is appropriate for the evaluation),

- implementation of the method close to one of the STORHY car manufacturers (noted CM1 in the following subsections),

- extension of the approach close to the other STORHY car manufacturers (details provided in subsection 3.4).

The approach and results provided in the next subsections are corresponding to the implementation of the method with $C M 1$.

A detailed overview of the input and output data that have been obtained during the implementation of MACBETH approach within STORHY project is provided in Appendices.

3.3.2 Structuring the context of the evaluation 
Let us recall that three alternatives (hydrogen storage systems) have been compared: a type IV $70 \mathrm{MPa}$ hydrogen storage system $\left(\mathrm{C}-\mathrm{H}_{2}\right)$, a cylindrical steel made liquid hydrogen storage system $\left(\mathrm{L}-\mathrm{H}_{2}\right)$ and a solid storage system. The final automotive application that has been considered as a framework for the comparison was a fuel cell vehicle with $6 \mathrm{~kg}$ of hydrogen on-board. The evaluation was focused on five technical evaluation criteria: system volume (1), system mass $(\mathrm{kg})$, refuelling time $(\mathrm{min})$, hydrogen loss rate $\left(\mathrm{g} / \mathrm{h} / \mathrm{kg}_{\mathrm{H} 2}\right)$ and conformability (constructed scale). Conformability was defined as the ability of the storage system to be shaped and included in an existing vehicle structure. The performances of these hydrogen storage technologies taken into account in this study are provided in Table 1.

Table 1: Performance table giving the performances of three hydrogen storage technologies, in the specific case of a $6 \mathrm{~kg}$ hydrogen fuel cell vehicle

\begin{tabular}{lllllll}
\hline Technologies & $\begin{array}{l}\text { System volume } \\
(\mathrm{l})\end{array}$ & $\begin{array}{l}\text { System } \\
(\mathrm{kg})\end{array}$ & $\begin{array}{l}\text { Refuelling time } \\
(\mathrm{min})\end{array}$ & $\begin{array}{l}\text { Hydrogen loss } \\
\text { rate }\left(\mathrm{g} / \mathrm{h} / \mathrm{kg}_{\mathrm{H} 2}\right)\end{array}$ & $\begin{array}{l}\text { Conformability } \\
\text { (constructed } \\
\text { scale) }\end{array}$ \\
\hline $\mathrm{C}-\mathrm{H}_{2}{ }^{\mathrm{a}}$ & 250 & 133 & 4 & 0 & -- \\
$\mathrm{L}_{\mathrm{H}}{ }^{\mathrm{b}}$ & 167 & 100 & 2 & 1.3 & -- \\
$\mathrm{Solid}^{\mathrm{c}}$ & 250 & 500 & 15 & 0 & - \\
\hline
\end{tabular}

atype IV $70 \mathrm{MPa}$ storage system

bylindrical steel made storage system

clow temperature metal hydride storage system

\subsubsection{Determining two reference levels for each evaluation criterion}

One of the specificities of the MACBETH method is the possibility to introduce two reference levels that have to be defined for each evaluation criterion. Originally in MACBETH method, these two reference levels are called "good" and "neutral". These two levels are extensively used in the assessment procedure of value functions and scaling constants in MACBETH. The terminology of these reference levels has been modified and adapted to the R\&D context of the evaluation in STORHY, in order to model the notion of R\&D efforts. Thus the level "neutral" has been changed into "acceptable" and the level "good" has been changed into "satisfying". The following definitions have been chosen for these two levels (Figure 4):

- "acceptable level": level below which a major R\&D effort will be required to allow the adoption of the technology.

- "satisfying level": level above which the criterion is a strong point of the technology and $R \& D$ for improving the performance regarding the studied criterion is no more a priority.

In order to illustrate this concept, let us consider the criterion "system volume", quoted $g_{\text {vol }}$ and expressed in litres. Car manufacturer $C M 1$ was asked to determine two values (expressed in litres), the one corresponding to a satisfying system volume and the other corresponding to an acceptable system volume, both in the case of the chosen final application. The values provided by CMI were the following: "acceptable system volume" at 150 litres, and the "satisfying system volume" at 80 litres (Figure 5). 


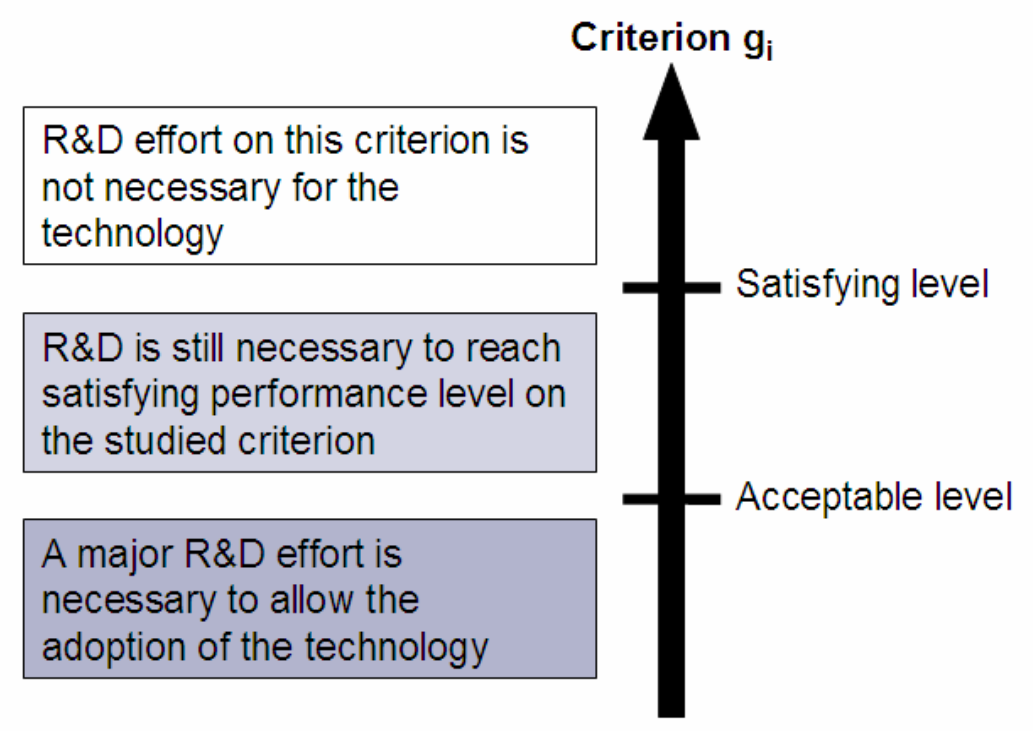

Figure 4: Definition of the two reference levels used in MACBETH method for the evaluation of R\&D.

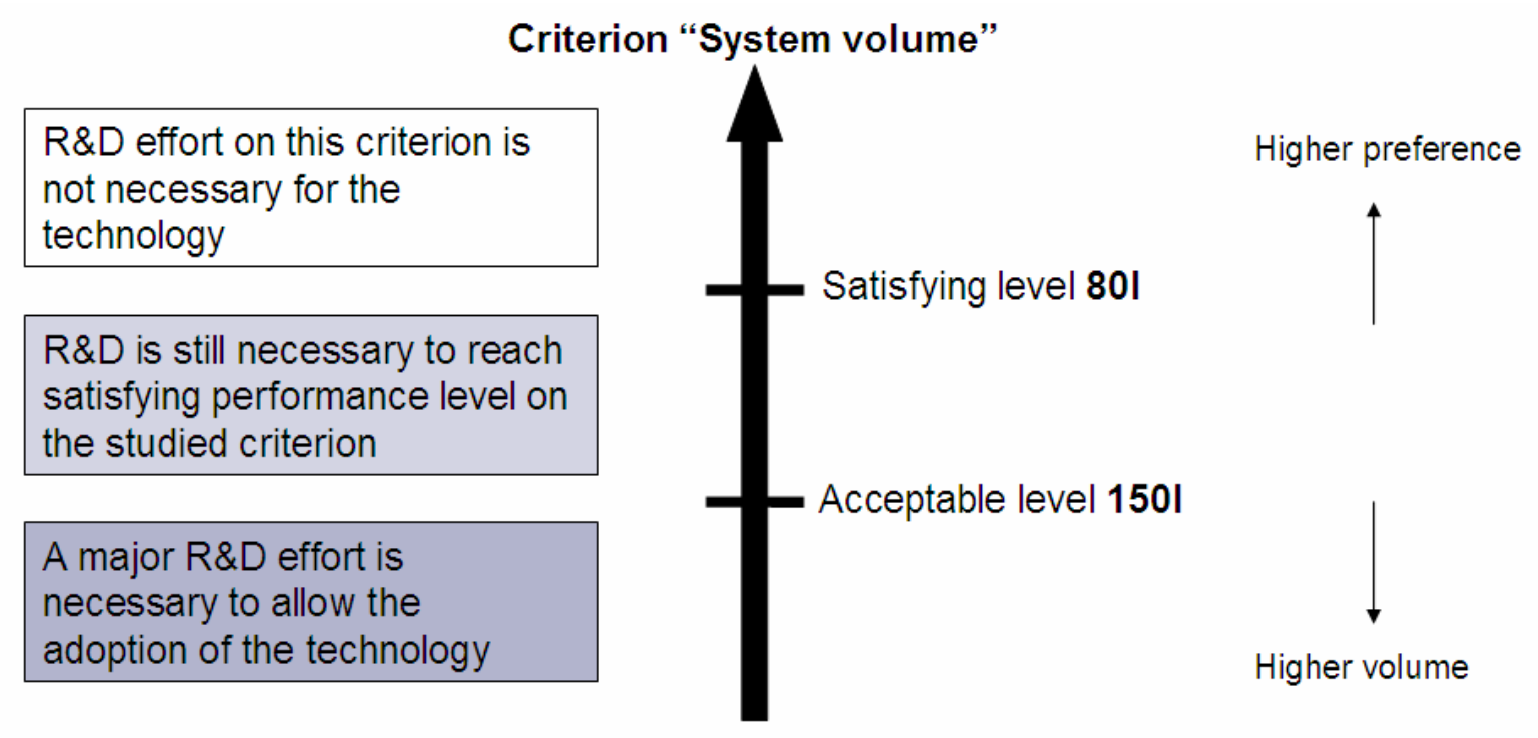

Figure 5: Representation of the acceptable and satisfying storage system volumes expressed by the interviewed car manufacturer $C M 1$ considering a fuel cell vehicle with $6 \mathrm{~kg}$ of hydrogen on-board.

$C M 1$ was then asked to answer to the same question for the other technical evaluation criteria and in the case of the same final application. Table 2 provides the set of values that have been obtained from the interactive definition of these reference levels. The participation of several car manufacturers for the implementation of this step was found to be difficult because of the strategic value of the information presented in this table.

Table 2: Set of values that have been obtained from car manufacturer CM1 concerning acceptable and satisfying reference levels for the five selected technical evaluation criteria, in the case of a fuel cell vehicle application with $6 \mathrm{~kg}$ of hydrogen on-board

\begin{tabular}{lllll}
$\begin{array}{l}\text { System volume } \\
(\mathrm{l})\end{array}$ & $\begin{array}{l}\text { System mass } \\
(\mathrm{kg})\end{array}$ & $\begin{array}{l}\text { Refuelling time } \\
(\mathrm{min})\end{array}$ & $\begin{array}{l}\text { Hydrogen loss } \\
\text { rate }\left(\mathrm{g} / \mathrm{h} / \mathrm{kg}_{\mathrm{H} 2}\right)\end{array}$ & $\begin{array}{l}\text { Conformability } \\
(\text { constructed }\end{array}$ \\
\hline
\end{tabular}




\begin{tabular}{llllll}
\hline & & & & \\
\hline Satisfying & 80 & 100 & 4 & 0 & scale) \\
Acceptable & 150 & 200 & 8 & 0.04 & "Good"a \\
\hline
\end{tabular}

"A "good" conformability meant that the system could be easily shaped and included in an existing vehicle structure.

${ }^{\mathrm{b}}$ A "low" conformability meant that the storage system was a constraint for the design of the vehicle.

\subsubsection{Ranking of the technologies}

Knowing the performances of the technologies (Table 1) and the reference levels expressed by CMI (Table 2), the hydrogen storage technologies were then ranked, for each evaluation criterion, as shown in Table 3.

Table 3: Ranking of the assessed hydrogen storage technologies regarding the previously defined satisfying and acceptable reference levels

\begin{tabular}{|c|c|c|c|c|}
\hline System volume (1) & System mass (kg) & $\begin{array}{l}\text { Refuelling time } \\
\text { (min) }\end{array}$ & $\begin{array}{l}\text { Hydrogen loss rate } \\
\left(\mathrm{g} / \mathrm{h} / \mathrm{kg}_{\mathrm{H} 2}\right)\end{array}$ & $\begin{array}{l}\text { Conformability } \\
\text { (constructed } \\
\text { scale) }\end{array}$ \\
\hline SAT (80) & $\mathbf{S A T}=\mathrm{L}-\mathrm{H}_{2}(100)$ & $\mathrm{L}-\mathrm{H}_{2}(2)$ & SAT $=$ C- $\mathrm{H}_{2}=$ Solid $(0)$ & SAT ("Good") \\
\hline $\mathrm{ACC}(150)$ & C- $\mathrm{H}_{2}(133)$ & $\mathbf{S A T}=\mathrm{C}-\mathrm{H}_{2}(4)$ & $\operatorname{ACC}(0.04)$ & ACC ("Low") \\
\hline${\mathrm{L}-\mathrm{H}_{2}}_{2}(167)$ & $\operatorname{ACC}(200)$ & $\mathbf{A C C}(8)$ & $\mathrm{L}-\mathrm{H}_{2}(1.3)$ & Solid \\
\hline $\mathrm{C}-\mathrm{H}_{2}=$ Solid $(250)$ & Solid (500) & Solid (15) & & $\mathrm{C}-\mathrm{H}_{2}$ \\
\hline & & & & $\mathrm{L}-\mathrm{H}_{2}$ \\
\hline
\end{tabular}

\subsubsection{Differences of attractiveness}

The aim of this step is to translate the original numerical scales $g_{i}$ into new scales $v_{i}$ for each criterion, using the notion of "differences of attractiveness" between alternatives. In MACBETH, seven semantic categories are used for qualifying the differences of attractiveness between alternatives: "extreme", "very strong", "strong", "moderate", "weak", "very weak", "no difference". This concept is illustrated in Figure 6 in the case of the "system volume" criterion. 


\section{Criterion "System volume"}



Figure 6: The car manufacturer was asked to qualify the difference of attractiveness between the performances of the hydrogen storage technologies, choosing among 7 semantic categories.

Using this semantic scale, the eventual non linearity of the judgment of car manufacturer CM1 could be modelled. Indeed for example, in terms of interest in improving the system volume, a reduction of 10 litres can have a different meaning at various places on the scale, e.g., between 901 and 801 and between 2301 and 2201 . Another advantage of this questioning procedure in MACBETH is that it is appropriate for taking into account the uncertainties of the raw performance data.

The information obtained at the end of this step was expressed by a dedicated matrix called "judgements matrix", for each evaluation criterion. Figure 7 provides the judgment matrix obtained for the "system volume" criterion. In this figure, "positive" means that the difference of attractiveness (for example between the acceptable level and $\mathrm{C}-\mathrm{H}_{2}$ ) has not been qualified specifically by $C M 1$, but due to the original ranking of the technologies, this difference of attractiveness is automatically set "positive" by the M-MACBETH software. 


\begin{tabular}{|c|c|c|c|c|c|c|}
\hline \multicolumn{6}{|c|}{ 곡 System volume } & $\mathbf{X}$ \\
\hline 罪 & Sat & $\mathrm{Acc}$ & $\mathrm{L} \cdot \mathrm{H} 2$ & $\mathrm{C} \cdot \mathrm{H}_{2}$ & Solid & extreme \\
\hline Sat & no & strong & positive & positive & positive & Y. strong \\
\hline $\mathrm{Acc}$ & & no & weak & positive & positive & strong \\
\hline L-H2 & & & no & strong & positive & moderate \\
\hline $\mathrm{C} \cdot \mathrm{H}_{2}$ & & & & no & no & weak \\
\hline Solid & & & & $m$ & $m$ & very weak \\
\hline \multirow{2}{*}{\multicolumn{7}{|c|}{ Consistent judgements }} \\
\hline & & & & & & \\
\hline 聿 & & 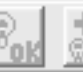 & 曲计 & H. 玨 & t & \\
\hline
\end{tabular}

Figure 7: Judgements matrix related to the system volume criterion, obtained close to $C M 1$.

These judgements were then processed by the M-MACBETH software using linear programming to build a scale of attractiveness reflecting these judgments. These scales were normalized with the acceptable reference level at 0 and the satisfying reference level at 100 (Figure 8).

\section{Criterion "System volume"}


Figure 8: Representation of the translation of the original numerical scale $g_{v o l}$ into a normalized scale of attractiveness $v_{v o l}$ (also called "MACBETH scale").

At the end of this step, five new numerical scales of attractiveness were then obtained (corresponding to the five technical evaluation criteria), each one being normalized with the acceptable reference level at 0 and the satisfying reference level at 100 . These scales were extensively discussed with $C M 1$, who finally approved the ones that we presented.

\subsubsection{Performance profiles}


Thanks to the previously described evaluation process, the performance profile of each hydrogen storage technology could be obtained. These performance profiles, provided in Figure 9, revealed the performance reached by each technology in the frame of the $6 \mathrm{~kg}$ hydrogen fuel cell vehicle application and according to the judgments of the interviewed car manufacturer CMI.
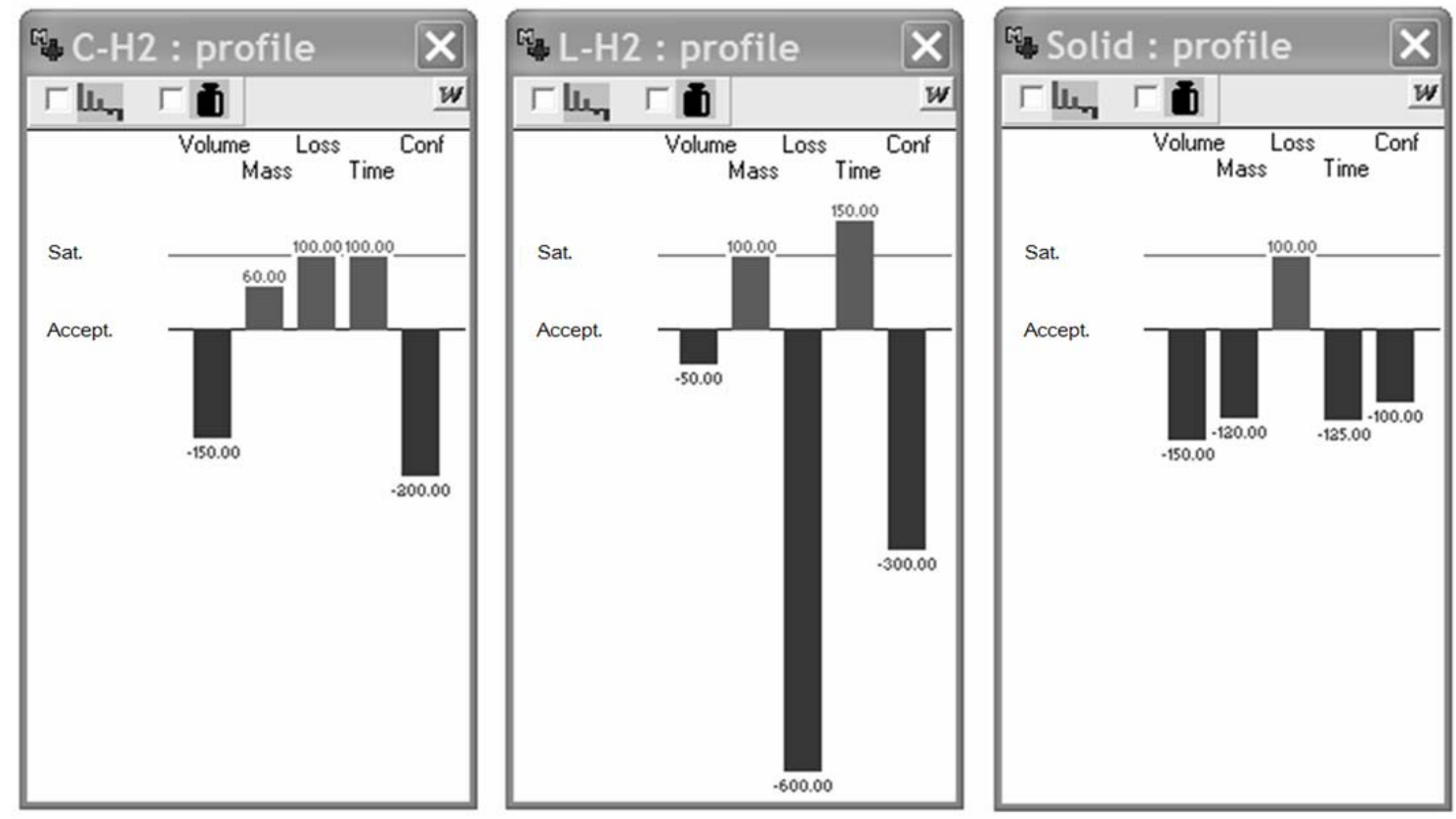

Figure 9: Performance profiles obtained for the evaluated hydrogen storage technologies, in the frame of a $6 \mathrm{~kg}$ hydrogen fuel cell vehicle application.

These performance profiles showed that each one of the evaluated hydrogen storage technologies was characterized by at least two "non acceptable" performances. Compressed hydrogen storage suffers from a large volume and a lack of conformability. Liquid hydrogen storage shows also a large volume, a low conformability, and a particularly high hydrogen loss rate. Solid storage exhibits a high volume, a high mass, a high refuelling time and a low conformability. These results are representing the most important issues to be focused on in terms of R\&D among the evaluation criteria that have been taken into account, and according to the vision of the interviewed car manufacturer $C M 1$. The results show that in the frame of a fuel cell vehicle application, volume remains a critical issue for all of the evaluated hydrogen storage technologies. None of the compressed, liquid and solid storage methods is situated above the "acceptable" performance level defined by CM1. In the same way, conformability is considered to be an important issue for all of the evaluated hydrogen storage technologies. None of the hydrogen technologies is considered as "acceptable" on this criterion and in the frame of the studied final application. Concerning mass, according to $C M 1$, none of the hydrogen storage technologies is situated above the "satisfying" reference level. However, compressed and liquid storage technologies are situated above the "acceptable" reference level defined by this end-user. Mass remains an issue especially for solid storage technology, for which the performance is evaluated below the "acceptable" reference level defined by CM1 and for this specific final application. Concerning refuelling time, compressed technology is considered "satisfying", liquid technology is "satisfying" and solid storage is positioned below the "acceptable" level. Finally, regarding hydrogen loss rate, the performance reached by compressed and solid storage technologies is satisfying, while the performance reached by liquid hydrogen storage technology is positioned far below the 
acceptable reference level, showing that this is the main critical issue of this technology, according to $C M 1$, and in the frame of the studied final application.

In addition to the previous steps, the evaluation process can be completed by an aggregation phase. This phase consists in determining scaling constants (weights) and processing a weighted-sum of the normalized scales of attractiveness obtained for each criterion. Such aggregation leads to a final global ranking of the technologies. The next subsections provide a description of how the scaling constants have been determined and the result of the overall aggregation that has been obtained close to $C M 1$.

\subsubsection{Determining scaling constants}

Following the MACBETH method, scaling constants were determined through the definition of fictitious alternatives $f_{i}$. A fictitious alternative $f_{i}$ is characterized by a satisfying performance for criterion $g_{i}$ and acceptable performances for all other criteria. For example, the fictitious hydrogen storage technology $f_{\text {vol }}$ is satisfying for system volume criterion $(801)$, and acceptable for all other criteria. Table 4 summarizes the performances of the five fictitious hydrogen storage technologies corresponding to the reference levels that have been specified by $C M 1$.

Table 4: Performances of the five fictitious hydrogen storage technologies related to the reference levels specified by $C M 1$

\begin{tabular}{lllllll}
\hline Technologies & $\begin{array}{l}\text { System volume } \\
(\mathrm{l})\end{array}$ & $\begin{array}{l}\text { System } \\
(\mathrm{kg})\end{array}$ & $\begin{array}{l}\text { Refuelling time } \\
(\mathrm{min})\end{array}$ & $\begin{array}{l}\text { Hydrogen loss } \\
\text { rate }\left(\mathrm{g} / \mathrm{h} / \mathrm{kg}_{\mathrm{H} 2}\right)\end{array}$ & $\begin{array}{l}\text { Conformability } \\
(\text { constructed } \\
\text { scale) }\end{array}$ \\
\hline$f_{\text {vol }}$ & $\mathbf{8 0}$ & 200 & 8 & 0.04 & Low \\
$f_{\text {mass }}$ & 150 & $\mathbf{1 0 0}$ & 8 & 0.04 & Low \\
$f_{\text {ref }}$ & 150 & 200 & $\mathbf{4}$ & 0.04 & Low \\
$f_{\text {loss }}$ & 150 & 200 & 8 & $\mathbf{0}$ & Low \\
$f_{\text {conf }}$ & 150 & 200 & 8 & 0.04 & Good \\
\hline
\end{tabular}

Then $C M 1$ was asked to rank these fictitious hydrogen technologies in terms of preferences by evaluating what would be the most interesting improvement, from acceptable level to satisfying level, among the five possibilities. CMI provided the following ranking (by order of preference):

$f_{\text {vol }}>f_{\text {mass }}>f_{\text {conf }}>f_{\text {ref }}>f_{\text {loss }}$

Such ranking means the improvement from 1501 to 801 is considered by $C M 1$ as the most interesting improvement among the five possibilities of improvement.

Then in order to calculate scaling constants, CMI was asked to evaluate the difference of attractiveness between these fictitious alternatives, using the same set of semantic categories as the one used in the previous phase, by answering questions such as "How do you judge the difference of attractiveness between $f_{\text {vol }}$ and $f_{\text {mass? }}$ ?" (in other words, "how do you judge the difference of attractiveness between i) improving system volume from 150 to $80 l$ and ii) reducing the system mass from 120 to $60 \mathrm{~kg}$ ?"). As in the previous phase, the information obtained at the end of this step was expressed by a dedicated "judgements matrix" summarizing the ranking and the difference of attractiveness between the fictitious alternatives (Figure 10). 


\begin{tabular}{|c|c|c|c|c|c|c|c|c|}
\hline \multicolumn{8}{|c|}{ 곡 Weighting (Global) } & \multirow{3}{*}{\begin{tabular}{|l|} 
extreme \\
Y. strong \\
\end{tabular}} \\
\hline 峴 & [Volume ] & [ Mass ] & [ Conform ] & [Refuel ] & [ Loss ] & [ toutes inf ] & $\begin{array}{l}\text { Current } \\
\text { scale }\end{array}$ & \\
\hline [Volume ] & no & weak-mod & positive & positive & positive & positive & 37.50 & \\
\hline [Mass] & & no & weak & positive & positive & positive & 29.16 & strong \\
\hline [ Conform ] & & & no & moderate & positive & positive & 20.83 & moderate \\
\hline [Refuel ] & & & & no & very weak & positive & 8.34 & weak \\
\hline [ Loss] & & & & & no & positive & 4.17 & no \\
\hline [ toutes inf ] & & & & & & no & 0.00 & \\
\hline \multicolumn{9}{|c|}{ Consistent judgements } \\
\hline 聿 & (8) & +1 自 & 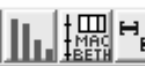 & 田 & 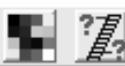 & & & \\
\hline
\end{tabular}

Figure 10: Judgements matrix representing the differences of attractiveness between fictitious alternatives.

These judgements were then processed by M-MACBETH software using linear programming, in order to calculate the scaling constants $w_{i}$ in accordance with the preferences expressed in the judgements matrix (Figure 11).

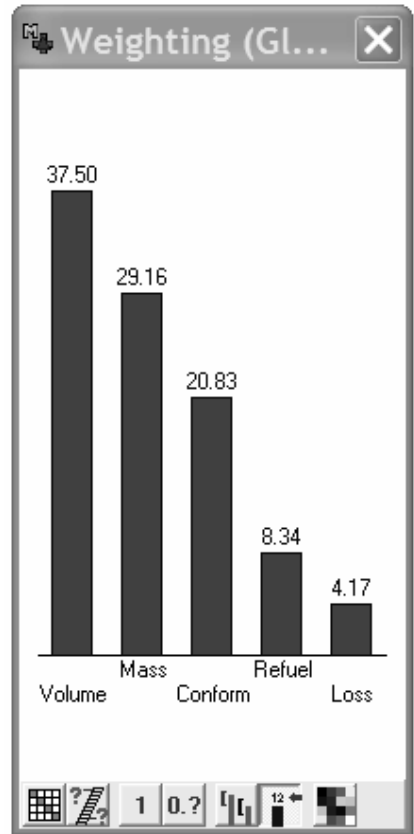

Figure 11: Scales constants $w_{i}$ calculated by M-MACBETH software, relying on the judgments matrix.

\subsubsection{Aggregation}

Based on the five normalized scales of attractiveness and the scaling constants (weights) $w_{i}$, the global evaluation quote of each hydrogen storage technology was easily calculated by MMACBETH software processing the weighted sum method:

$$
\begin{aligned}
& v\left(\mathrm{CH}_{2}\right)=\sum_{i=1}^{5} w_{i} v_{i}\left(g_{i}\left(\mathrm{CH}_{2}\right)\right) \\
& v\left(\mathrm{LH}_{2}\right)=\sum_{i=1}^{5} w_{i} v_{i}\left(g_{i}\left(\mathrm{LH}_{2}\right)\right)
\end{aligned}
$$


$v($ Solid $)=\sum_{i=1}^{5} w_{i} v_{i}\left(g_{i}(\right.$ Solid $\left.)\right)$

Finally, the result of this aggregation phase could be represented using a single global scale of attractiveness (Figure 12). This result showed that in the frame of the studied fuel cell vehicle application, none of the three evaluated hydrogen storage technologies reaches the "acceptable" reference level. That is to say that strong R\&D efforts are still needed from a technical point of view, for each one of the evaluated technologies.

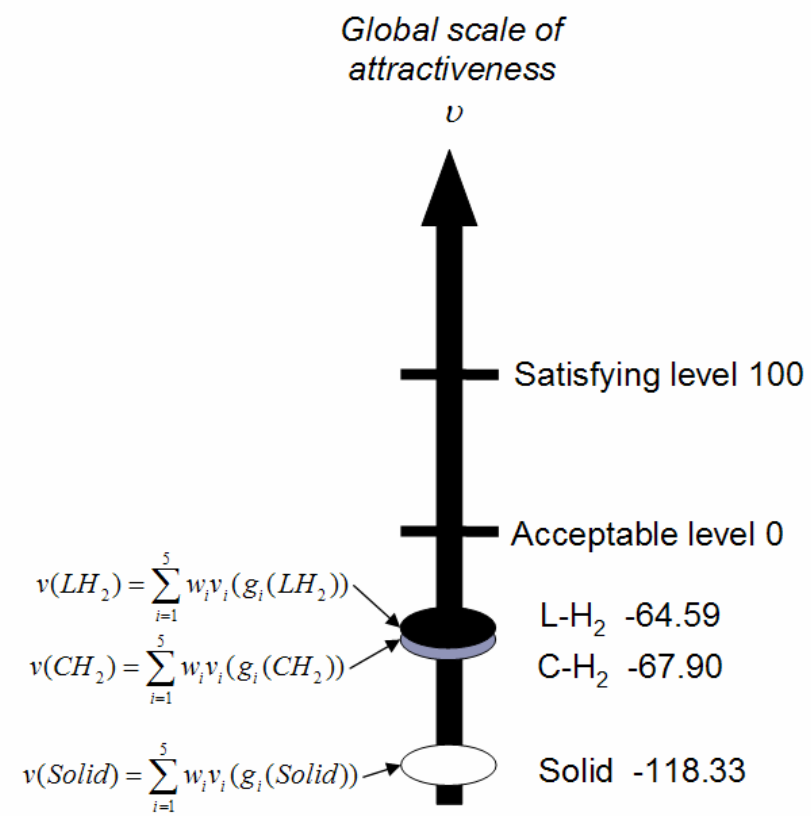

Figure 12: Global scale of attractiveness obtained at the end of the implementation of the MACBETH method close to $C M 1$.

To conclude, the implementation process conducted close to CMI and presented in the previous subsections revealed the added-value of MACBETH approach in the case of an "application-oriented" evaluation. Relying on (i) the performance of the storage technologies, (ii) the reference levels and (iii) the judgements formulated by $C M 1$, performance profiles of the hydrogen storage technologies were obtained, showing the remaining R\&D efforts that should be made, for each technology, in order to reach the targets settled by CM1.

The use of MACBETH close to CEA experts and close to CM1 showed the added value of this method in particular for comparing the points of view of multiple actors.

However, within STORHY project, the conclusions obtained from the implementation of MACBETH method close to CMI could not be considered as "STORHY conclusions". Indeed, global STORHY conclusions could have been drawn only if the whole stakeholders of the study could provide their reference levels and judgements; in such case the consensual results between the implementations could have been identified and could have been considered as STORHY conclusions. Many tasks of the MACBETH methodology process lead to provide representations of strategic visions. For instance, giving precise numerical value to the two reference levels described above is a strategic signal of what is considered by the car manufacturer as an internal admitted target. 
The next subsection describes how the extension of the evaluation approach has been conducted close to the other STORHY car manufacturers.

3.4 Extension of the approach within STORHY project: towards an "improved performance table"

The work described in this subsection has been conducted by the CEA after the end of the collaboration with the LAMSADE team. The following paragraphs are showing that the use of "reference levels" allowed structuring the discussion between SP Evaluation and the STORHY stakeholders.

The consequences of the competing context between stakeholders on the evaluation process within STORHY project

As described in the previous subsections, MACBETH method was implemented interactively with one stakeholder for the evaluation and comparison of the technical performance of hydrogen storage technologies in the case of an "application-oriented" evaluation (a fuel cell vehicle with a storage capacity of $6 \mathrm{~kg}$ of hydrogen). Once this implementation has been completed, the CEA proposed to the other STORHY stakeholders to implement the evaluation method using this same "application-oriented" evaluation approach. Finally STORHY stakeholders decided not to proceed to "application-oriented' evaluations, but rather evaluations relying on relative parameters independently from any specific final application. This change was the consequence of the fact that STORHY stakeholders are in competition on the automotive market and each car manufacturer gets his own specific final applications and does not necessarily want to share his targets and visions with competing companies even when working in the same EU Research project.

New set of evaluation criteria using relative parameters instead of absolute ones In this context, the proposal of the analyst was to take into account new evaluation criteria for the evaluation and comparison of the hydrogen storage technologies, in accordance with the wish of the stakeholders: system volumetric energy density (instead of system volume), system gravimetric energy density (instead of system mass), system refuelling rate (instead of system refuelling time), hydrogen loss rate was kept the same, as well as conformability. The objective of the analyst was then to identify the whole stakeholders' consensual vision of the performance of the technologies using the newly defined evaluation criteria and to collect their judgements on the remaining R\&D needs for each technology.

\section{Building a consensual "improved performance table"}

In this context, it was agreed between STORHY stakeholders and the analyst to establish an "improved performance table" which could represent both performance of the technologies and qualitative evaluation of the remaining R\&D efforts. To do so, the analyst proposed that car manufacturers could provide acceptable and satisfying reference levels for these new evaluation criteria. The definition of the reference levels was kept unchanged as in MACBETH procedure (strong remaining research efforts below the acceptable level, moderate research efforts between acceptable and satisfying reference levels, slight/no more research efforts above the satisfying reference level). Once these reference levels data were obtained, the "improved performance table" could be built by the analyst and was then validated by STORHY stakeholders (Table 5). In addition to hydrogen storage technologies, STORHY stakeholders proposed to show also the performance of a competing energy storage technology (Li-Ion battery) and the performance of reference gasoline tank. 
Table 5: Final STORHY performance table built in cooperation between SP Evaluation and SP Users

\begin{tabular}{|c|c|c|c|c|c|}
\hline & $\begin{array}{c}\text { Volumetric } \\
\text { energy density } \\
(\mathrm{kWh} / \mathrm{l})\end{array}$ & $\begin{array}{c}\text { Gravimetric } \\
\text { energy density } \\
(\mathrm{kWh} / \mathrm{kg})\end{array}$ & $\begin{array}{c}\text { Refuelling } \\
\text { rate } \\
(\mathrm{kWh} / \mathrm{min})\end{array}$ & $\begin{array}{c}\text { Hydrogen loss } \\
\text { rate } \\
(\mathrm{g} / \mathrm{h} / \mathrm{kg})\end{array}$ & $\begin{array}{c}\text { Conformability } \\
1=\text { cylindrical } \\
5=\text { complex }\end{array}$ \\
\hline $\mathrm{C}-\mathrm{H}_{2} 350$ bar storage system & 0.5 & 1.3 & 50 & 0 & 2 \\
\hline $\begin{array}{l}\text { STORHY C- } \mathrm{H}_{2} 700 \text { bar storage system } \\
\text { Type III }\end{array}$ & 0.8 & 1.3 & 50 & 0 & 2 \\
\hline $\begin{array}{l}\text { STORHY C- } \mathrm{H}_{2} 700 \text { bar storage system } \\
\text { Type IV }\end{array}$ & 0.8 & 1.5 & 50 & 0.002 & 2 \\
\hline L- $\mathrm{H}_{2}$ conventional & 1.2 & 2.0 & 100 & 1.3 & 1 \\
\hline STORHY L-H ${ }_{2}$ cylindrical & 1.3 & 5.0 & 100 & 1.0 & 1 \\
\hline STORHY L-H ${ }_{2}$ Free-form demonstrator & 1.2 & 5.9 & 100 & 0.8 & 4 \\
\hline $\begin{array}{l}\text { Solid storage } \\
\text { Low temp. hydrides }\end{array}$ & 0.8 & 0.4 & 13 & 0 & 3 \\
\hline $\begin{array}{l}\text { STORHY Solid storage } \\
\mathrm{NaAlH}_{4} \text { Pilot tank } \\
\end{array}$ & 0.7 & 0.3 & 25 & 0 & 3 \\
\hline $\begin{array}{l}\text { STORHY Solid storage } \\
\mathrm{NaAlH}_{4} \text { Forecast } \\
\end{array}$ & 1.2 & 0.7 & 25 & 0 & 3 \\
\hline Li Ion Battery & 0.2 & 0.1 & 0.5 & 0 & 4 \\
\hline Gasoline Tank & 7.0 & 8.0 & $>200$ & 0 & 5 \\
\hline & \multirow{3}{*}{ Caption : } & \multicolumn{2}{|c|}{$\begin{array}{l}\text { Strong R\&D efforts } \\
\text { recommended }\end{array}$} & & \\
\hline & & \multicolumn{2}{|c|}{$\begin{array}{l}\text { Still remaining R\&D } \\
\text { efforts }\end{array}$} & & \\
\hline & & \multicolumn{2}{|c|}{$\begin{array}{l}\text { Slight/No more R\&D } \\
\text { efforts necessary }\end{array}$} & & \\
\hline
\end{tabular}

\section{Comments on the case and on the decision aiding process}

4.1 The specific context of an integrated European research project: a multi-actor context, no single decision maker, several stakeholders in competition

The STORHY project was an integrated European research project aiming at developing three competing hydrogen storage technologies. A subproject Evaluation has been created so that the results of the STORHY project could be assessed and the remaining R\&D efforts for each technology could be identified. The specificities of the context in which the evaluation had to be achieved were the following:

- the client of the project was the European Commission,

- thirty-four academic and industrial partners were involved in the project,

- the aim of the project was to investigate the three main competing hydrogen storage technologies under development (pressure, liquid and solid),

- among these actors, there was no single decision maker but several stakeholders in competition,

- the mission of the subproject Evaluation (analyst) was then to conduct an objective and consensual evaluation and comparison of the technologies. Thus the terminology used for this study was not "decision aid" but "evaluation aid".

The support of the LAMSADE laboratory occurred about two years after the beginning of the STORHY project; at this time the problematic of the evaluation of the storage systems was already structured and the LAMSADE team did not participate to the structuring step and the definition of appropriate evaluation criteria. The support of LAMSADE team was conducted in an already structured context in which the evaluation criteria had been chosen before having studied deeply the whole evaluation problematic. From this experience within 
STORHY European project, the LAMSADE team recommends strongly to focus extensively on the structuring step for the future evaluations in further European projects.

4.2 The interest of MACBETH approach for the "application-oriented" multicriteria evaluation of technologies under development

From an early discussion between the stakeholders and the analyst, focus has been made on the technical performance of the hydrogen storage technologies. At first, five technical evaluation criteria were taken into account (system volume, system mass, refuelling time, hydrogen loss rate and conformability). The analyst identified MACBETH approach as a potentially appropriate method for evaluating and comparing technical performance of hydrogen storage technologies conducting "application-oriented" multicriteria evaluations close to the STORHY car manufacturers. The approach has been implemented successfully close to one of the STORHY car manufacturers. The results of this implementation showed that MACBETH approach seemed adapted for evaluating technologies that are under development and for comparing their performance to the targets of the end-users or stakeholders when a final application is well identified and specified (subsection 3.3).

In particular, the definition of "acceptable" and "satisfying" reference levels appeared to be helpful for the stakeholder. The performance profiles obtained at the end of the implementation process were showing clearly the strong and weak points, the remaining research efforts that have to be performed in order to bring the technologies above the acceptable level.

4.3 Multicriteria evaluation in a multi-actor R\&D context: the central role of the performance table

The reluctance of the stakeholders for "black boxes" and data aggregation

Despite the interesting outcomes of the implementation of MACBETH approach for application-oriented evaluation, some limits in the interpretation and use of the results could be identified. In particular, the notion of criteria aggregation was sometimes considered as a "loss of information". In general, within the whole duration of the project, STORHY stakeholders considered that criteria aggregation would be too much subjective and not appropriate for the evaluation in such a competing context. As a consequence, the possibilities of "local evaluation domain aggregation" and "global inter-domain aggregation" were set aside.

\section{An improved performance table}

Despite the differences between the visions of the stakeholders, the consensual evaluation of the technical performance of the hydrogen storage technologies could be achieved thanks to an "improved performance table" (Table 5). The analyst focused on the validation of the raw performance data of the state-of-the-art and STORHY prototypes. The stakeholders agreed about the use of relative parameters instead of absolute parameters. Once these data were validated by STORHY stakeholders, the analyst asked the stakeholders to provide their judgement on the acceptable and satisfying reference levels for these criteria, using the same definition as for the MACBETH procedure. Thus an improved performance table could be obtained, showing both the raw performance of the technologies and the remaining R\&D efforts that have been consensually identified by the stakeholders. For more detailed information on STORHY project evaluation and technical results, the reader can refer to STORHY final event presentations available in [8]. 


\section{Acknowledgments}

The authors wish to thank the European Commission for financial support of the Integrated Project STORHY Hydrogen Storage Systems for Automotive Application (Contract No SES6-CT-2004-502667) within the sixth RTD Framework Programme.

\section{References}

[1] IPCC, 2007. Climate Change 2007: Synthesis Report. Contribution of Working Groups I, II and III to the Fourth Assessment Report of the Intergovernmental Panel on Climate Change [Core Writing Team, Pachauri, R.K and Reisinger, A. (eds.)]. IPCC, Geneva, Switzerland, 104 pp.

[2] Goltsov VA, Veziroglu TN. A step on the road to Hydrogen Civilization. Int J Hydrogen Energy 2002;27:719-723.

[3] Goltsov VA, Veziroglu TN, Goltsova LF. Hydrogen civilization of the future - A new conception of the IAHE. Int J Hydrogen Energy 2006;31:153-159.

[4] Cherry RS. A hydrogen utopia? Int J Hydrogen Energy 2004;29:125-129.

[5] Dunn S. Hydrogen futures: toward a sustainable energy system. Int J Hydrogen Energy 2002;27:235-264.

[6] Ewan BCR, Allen RWK. A figure of merit assessment of the routes to hydrogen. Int J Hydrogen Energy 2005;30:809-819.

[7] Schlapbach L, Zuttel A. Hydrogen storage materials for mobile applications. Nature 2001;414:353-58.

[8] Strubel V. STORHY objectives and results. Final event presentation (available at www.storhy.net), 2008.

[9] Roy B. Méthodologie multicritère d'aide à la decision, Economica, Paris, 1985.

[10] Roy B, Bouyssou D. Aide multicritère à la décision, Méthodes et cas, Economica, 1993.

[11] Bana e Costa C, Vansnick JC. On the mathematical foundations of Macbeth. In: Figueira J, Greco S, Ehrgott M, editors. Multiple criteria decision analysis: state of the art surveys. Boston, Dordrecht, London: Springer Verlag, 2005. p. 409-442.

[12] Bana e Costa C, De Corte JM, Vansnick JC. Macbeth. LSE OR Working Paper 03.56. London School of Economics, 2003.

[13] Bana e Costa C, Vansnick JC. Applications of the Macbeth approach in the framework of an additive aggregation model. Journal of Multicriteria Decision Analysis, vol. 6, pp. 107-114, 1997.

[14] Bana e Costa C, Vansnick JC. A theoretical framework for measuring attractiveness by a categorical based evaluation technique (MACBETH), in Joao Climaco, Multicriteria Decision Analysis, pp. 15-24, Springer, 1997. 


\section{Appendix}

\section{Detailed input and output data obtained during the implementation process of MACBETH method within STORHY project}

In the following paragraphs, the detailed input and output data obtained during the implementation process of MACBETH method within STORHY project is provided.

\section{Interviewed actors:}

The MACBETH method has been implemented close to three experts. These experts are referenced as "expert 1", "expert 2" and "expert 3 " in the following paragraphs.

\section{Final application:}

For each one of these experts, the considered final application was a "fuel cell private car, with a storage capacity of $6 \mathrm{~kg}$ of hydrogen and a corresponding autonomy of $600 \mathrm{~km}$ ".

\section{Alternatives to be studied:}

The hydrogen storage technologies that have been compared were:

- compressed hydrogen storage at 700 bar

- liquid hydrogen storage

- solid storage using alanates materials

In addition to these hydrogen storage technologies, expert 2 considered that it would be useful to take into account another solid storage technology, i.e. solid storage using low temperature metal hydrides.

To complete the evaluation, two reference storage technologies have also been taken into account:

- compressed natural gas storage

- gasoline storage

\section{Evaluation criteria:}

The evaluation criteria that have been considered were:

- $\quad$ system mass $(\mathrm{kg})$

- $\quad$ system volume (1)

- refuelling time (min)

- hydrogen loss rate $\left(\mathrm{g} / \mathrm{h} / \mathrm{kgH}_{2}\right)$

- conformability (qualitative criterion)

\section{Reference levels chosen by the interviewed experts:}

As described previously in the article, the evaluation model is built relying on two reference levels for each criterion:

- acceptable level: below this level of performance, a strong technological improvement is necessary from the point of view of the interviewed expert and for the assessed final application 
- satisfying level: above this level, the research for improving the performance on this criterion is no more a priority

The following table provides the values chosen by the interviewed experts for these reference levels.

\begin{tabular}{|l|l|c|c|c|}
\cline { 3 - 5 } \multicolumn{2}{c|}{} & Expert 1 & Expert 2 & Expert 3 \\
\hline \multirow{2}{*}{ Volume } & ACC & 255 litres & 250 litres & 150 litres \\
\cline { 2 - 5 } & SAT & 74 litres & 120 litres & 80 litres \\
\hline \multirow{2}{*}{ Mass } & ACC & $142 \mathrm{~kg}$ & $150 \mathrm{~kg}$ & $200 \mathrm{~kg}$ \\
\cline { 2 - 5 } & SAT & $100 \mathrm{~kg}$ & $80 \mathrm{~kg}$ & $100 \mathrm{~kg}$ \\
\hline \multirow{2}{*}{ Conformability } & ACC & non quantified & non quantified & non quantified \\
\cline { 2 - 5 } & SAT & non quantified & non quantified & non quantified \\
\hline \multirow{2}{*}{$\mathrm{H}_{2}$ loss rate } & ACC & $0.1 \mathrm{~g} / \mathrm{h} / \mathrm{kg}$ & $0.5 \%$ & $0.1 \%$ \\
\cline { 2 - 5 } & SAT & $0.05 \mathrm{~g} / \mathrm{h} / \mathrm{kg}$ & 0 & 0 \\
\hline \multirow{2}{*}{ Refuelling time } & ACC & $6 \mathrm{~min}$ & $10 \mathrm{~min}$ & $8 \mathrm{~min}$ \\
\cline { 2 - 5 } & SAT & $3 \mathrm{~min}$ & $3 \mathrm{~min}$ & $4 \mathrm{~min}$ \\
\hline
\end{tabular}

Table 6 : Reference levels defined by the interviewed experts.

\section{Performance tables:}

The following tables are providing the raw physical data that have been used by the interviewed experts for the elaboration of the evaluation models.

Criterion "Volume" (expressed in litres)

\begin{tabular}{|l|c|c|c|}
\hline & Expert 1 & Expert 2 & Expert 3 \\
\hline LIQ & 207 & $210-220$ & 260 \\
\hline PRE & 255 & 240 & 326 \\
\hline SOLA & 300 & $250-300$ & 370 \\
\hline SOLH & 175 & $150-200$ & - \\
\hline GAZ & 220 & $210-220$ & 280 \\
\hline ESS & 60 & 60 & 60 \\
\hline SAT & 74 & 120 & 80 \\
\hline ACC & 255 & 250 & 150 \\
\hline
\end{tabular}

Table 7: Performance table for criterion "volume".

Criterion "Mass" (expressed in $\mathrm{kg}$ )

\begin{tabular}{|l|c|c|c|}
\hline & Expert 1 & Expert 2 & Expert 3 \\
\hline LIQ & 117,5 & $110-120$ & 117,5 \\
\hline PRE & 142 & 142 & 142 \\
\hline SOLA & 500 & 500 & 500 \\
\hline SOLH & 175 & 500 & - \\
\hline GAZ & 142 & 142 & 142 \\
\hline ESS & 51,5 & 51,5 & 51,5 \\
\hline SAT & 100 & 80 & 100 \\
\hline ACC & 142 & 150 & 200 \\
\hline
\end{tabular}

Table 8: Performance table for criterion "mass".

Criterion "Conformability" (constructed scale) 


\begin{tabular}{|l|c|c|c|}
\hline & Expert 1 & Expert 2 & Expert 3 \\
\hline LIQ & - & - & 4 \\
\hline PRE & - & - & 7 \\
\hline SOLA & - & - & 5 \\
\hline SOLH & - & - & - \\
\hline GAZ & - & - & 6 \\
\hline ESS & - & - & 1 \\
\hline SAT & BC & BC & 2 \\
\hline ACC & MC & MC & 3 \\
\hline
\end{tabular}

Table 9: Performance table for criterion "conformability".

Criterion "Hydrogen loss rate" (g/h/kg, or \% per day)

\begin{tabular}{|l|c|c|c|}
\hline & Expert 1 & Expert 2 & Expert 3 \\
\hline LIQ & 1,25 & 1,25 & 1,25 \\
\hline PRE & 0,0001 & $5 \varepsilon$ & 0,0001 \\
\hline SOLA & 0 & $\varepsilon$ & 0 \\
\hline SOLH & - & $\varepsilon$ & - \\
\hline GAZ & 0 & 0 & 0 \\
\hline ESS & 0 & 0 & 0 \\
\hline SAT & 0,05 & 0 & 0 \\
\hline ACC & 0,1 & $0,5 \%$ & $0,1 \%$ \\
\hline
\end{tabular}

Table 10: Performance table for criterion "hydrogen loss rate".

Criterion "Refuelling time" (minutes)

\begin{tabular}{|l|c|c|c|}
\hline & Expert 1 & Expert 2 & Expert 3 \\
\hline LIQ & 1,7 & 6 & 1,7 \\
\hline PRE & 6 & 6 & 6 \\
\hline SOLA & 30 & 15 & 30 \\
\hline SOLH & - & 15 & - \\
\hline GAZ & 3 & 3 & 2 \\
\hline ESS & 2 & $3-2$ & 4 \\
\hline SAT & 3 & 3 & 8 \\
\hline ACC & 6 & 10 & 3 \\
\hline
\end{tabular}

Table 11: Performance table for criterion "refuelling time".

\section{$\underline{\text { Judgment matrices for each expert: }}$}

The following figures are providing the judgement matrices obtained from the interviewed experts. These matrices are showing the positioning of the technologies in terms of differences of attractiveness. These differences of attractiveness have been expressed thanks to the MACBETH qualitative scale as described in the article.

\section{Expert 1:}




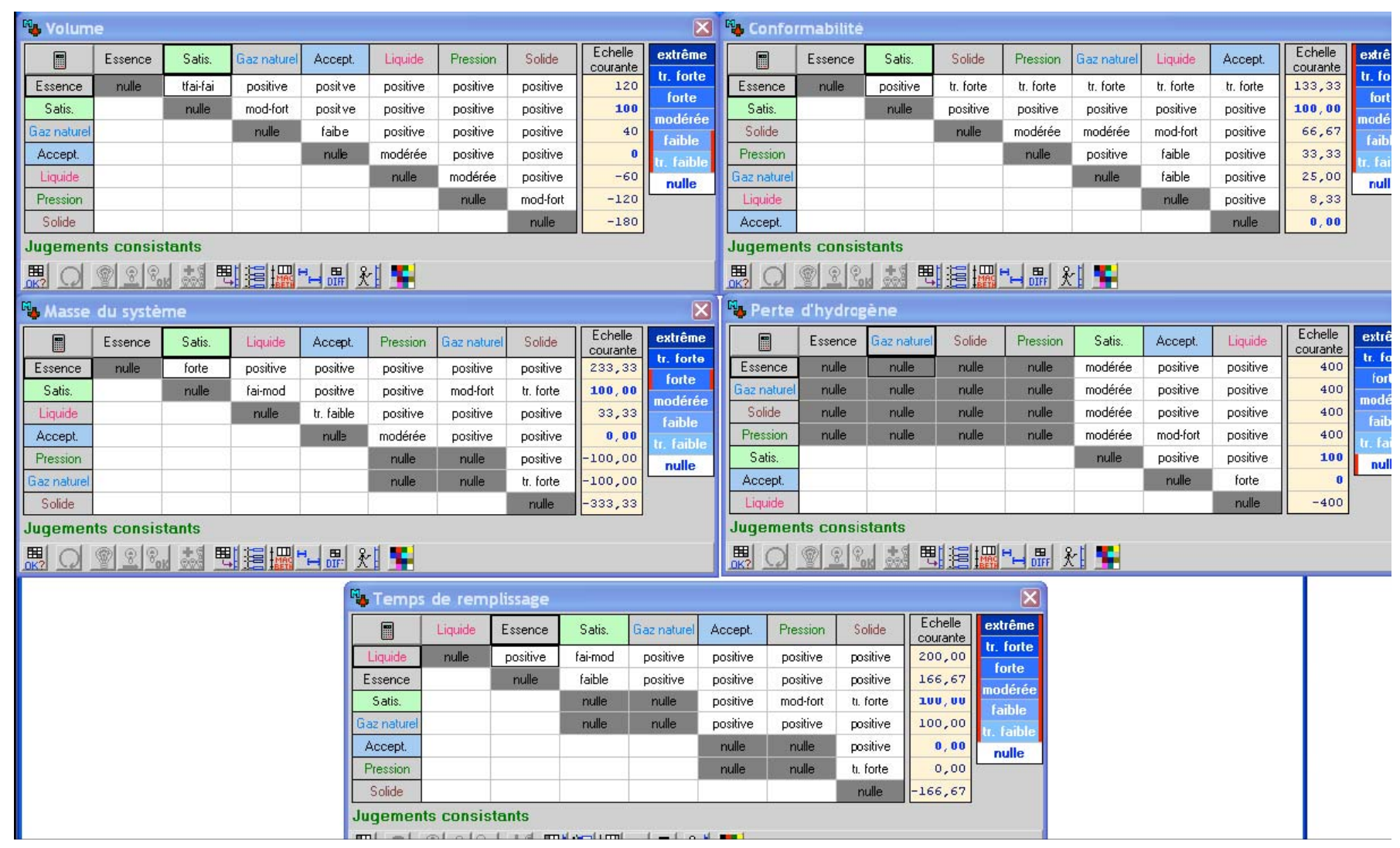

Figure 13 : Matrices of attractiveness obtained from Expert 1.

\section{Expert 2:}

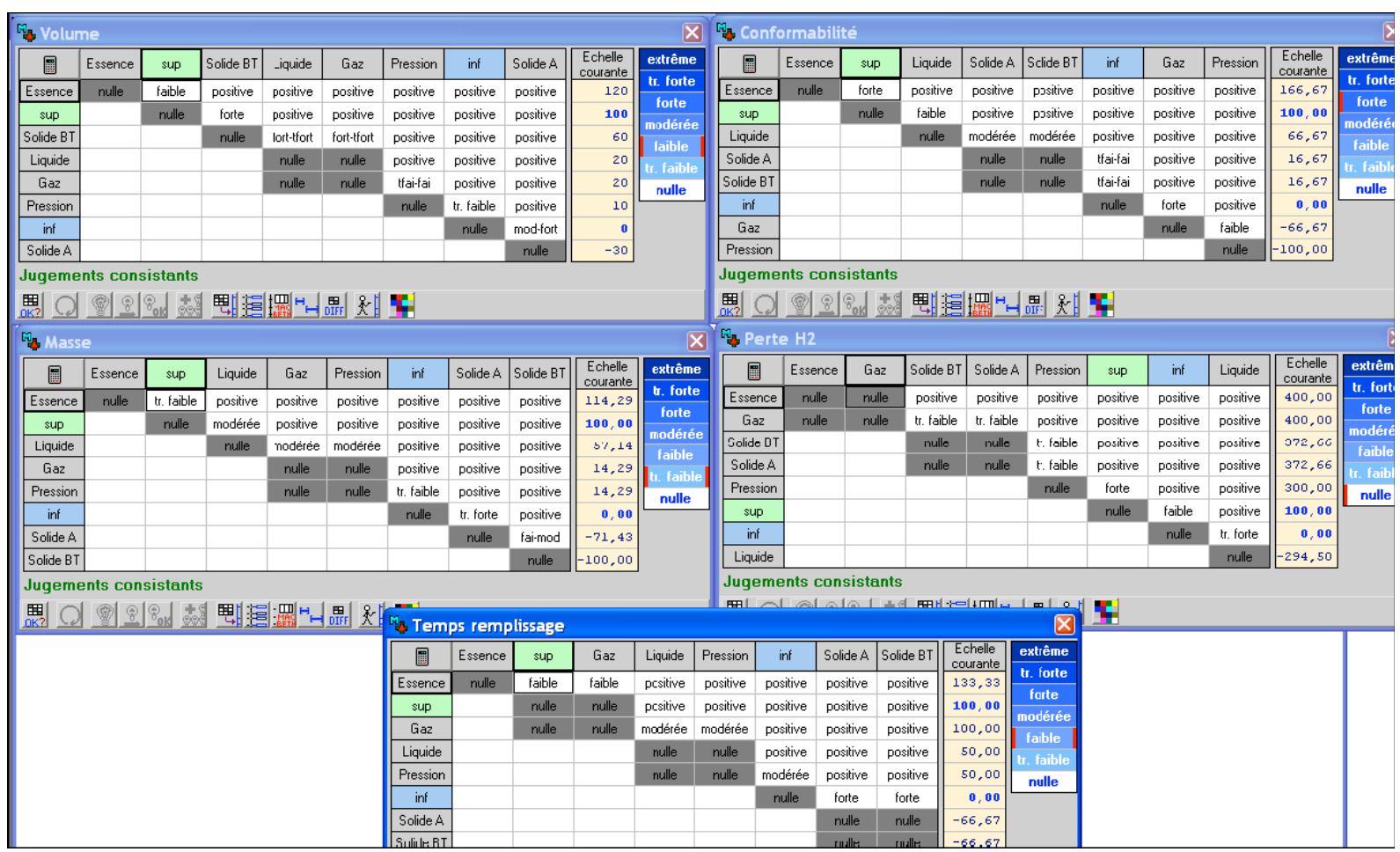

Figure 14 : Matrices of attractiveness obtained from Expert 2. 
Expert 3:

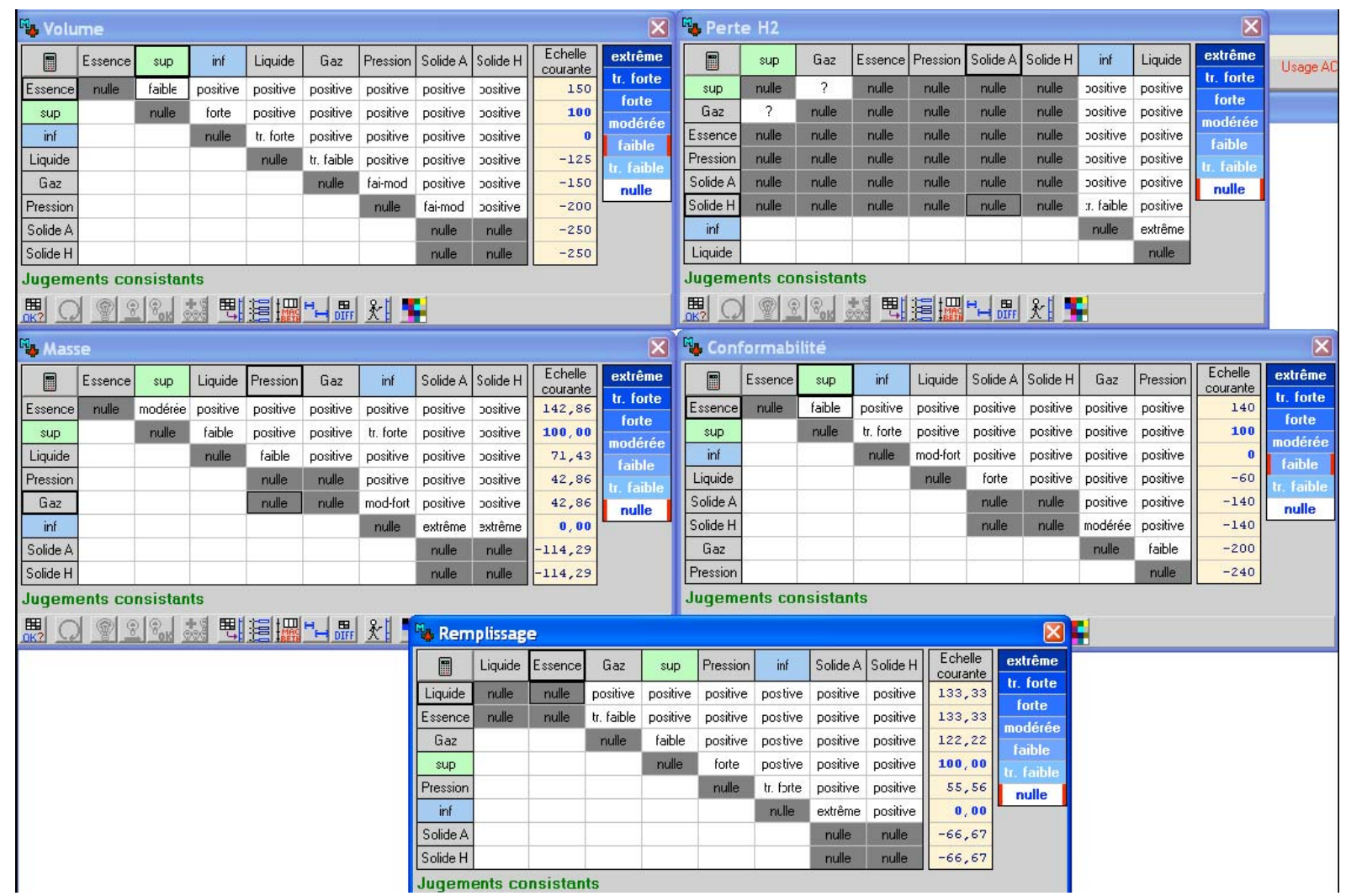

Figure 15 : Matrices of attractiveness obtained from Expert 3.

\section{MACBETH scales:}

Thanks to the judgment matrices filled with the experts' judgements, the M-MACBETH software proposed new normalized numerical scales, called "MACBETH scales". The following table provides the numerical values that have been attributed to the technologies, for each criterion.

\begin{tabular}{|c|c|c|c|c|c|c|c|c|c|c|c|c|c|c|c|}
\hline & \multicolumn{3}{|c|}{ Volume } & \multicolumn{3}{|c|}{ Mass } & \multicolumn{3}{|c|}{ Conformability } & \multicolumn{3}{|c|}{$\mathrm{H}_{2}$ loss rate } & \multicolumn{3}{|c|}{ Refuelling time } \\
\hline & $\begin{array}{c}\text { Exp. } \\
1 \\
\end{array}$ & $\begin{array}{c}\text { Exp. } \\
2 \\
\end{array}$ & $\begin{array}{c}\text { Exp. } \\
3\end{array}$ & $\begin{array}{c}\text { Exp. } \\
1 \\
\end{array}$ & $\begin{array}{c}\text { Exp. } \\
2 \\
\end{array}$ & $\begin{array}{c}\text { Exp. } \\
3 \\
\end{array}$ & $\begin{array}{c}\text { Exp. } \\
1 \\
\end{array}$ & $\begin{array}{c}\text { Exp. } \\
2\end{array}$ & $\begin{array}{c}\text { Exp. } \\
3 \\
\end{array}$ & $\begin{array}{c}\text { Exp. } \\
1 \\
\end{array}$ & $\begin{array}{c}\text { Exp. } \\
2\end{array}$ & $\begin{array}{c}\text { Exp. } \\
3 \\
\end{array}$ & $\begin{array}{c}\text { Exp. } \\
1 \\
\end{array}$ & $\begin{array}{c}\text { Exp. } \\
2 \\
\end{array}$ & $\begin{array}{c}\text { Exp } \\
3 \\
\end{array}$ \\
\hline SOLH & & 60 & & & -100 & & & 17 & & & 350 & & & -66 & \\
\hline SOLA & -180 & -30 & -300 & -333 & -71 & -86 & 66 & 17 & -140 & 400 & 350 & 100 & -166 & -66 & -66 \\
\hline PRE & -120 & 10 & -211 & -100 & 14 & 43 & 33 & -100 & -240 & 400 & 300 & 100 & 0 & 50 & 56 \\
\hline LIQ & -60 & 20 & -125 & 33 & 57 & 71 & 8 & 66 & -60 & -400 & -250 & -600 & 200 & 50 & 133 \\
\hline ESS & 120 & 120 & 150 & 233 & 114 & 143 & 133 & 166 & 140 & 400 & 400 & 100 & 166 & 133 & 133 \\
\hline GAZ & 40 & 20 & 150 & -100 & 14 & 43 & 25 & -66 & -200 & 400 & 400 & 100 & 100 & 100 & 122 \\
\hline ACC & 0 & 0 & 0 & 0 & 0 & 0 & 0 & 0 & 0 & 0 & 0 & 0 & 0 & 0 & 0 \\
\hline SAT & 100 & 100 & 100 & 100 & 100 & 100 & 100 & 100 & 100 & 100 & 100 & 100 & 100 & 100 & 100 \\
\hline
\end{tabular}

Table 12 : Values proposed by the M-MACBETH software as one possible solution corresponding to the qualitative data provided by the interviewed experts in the judgment matrices.

\section{Judgment matrices for the weighting of the criteria and global scales:}

The MACBETH scales as well as the judgement matrices for the weighting of the criteria are provided below.

Expert 1: 


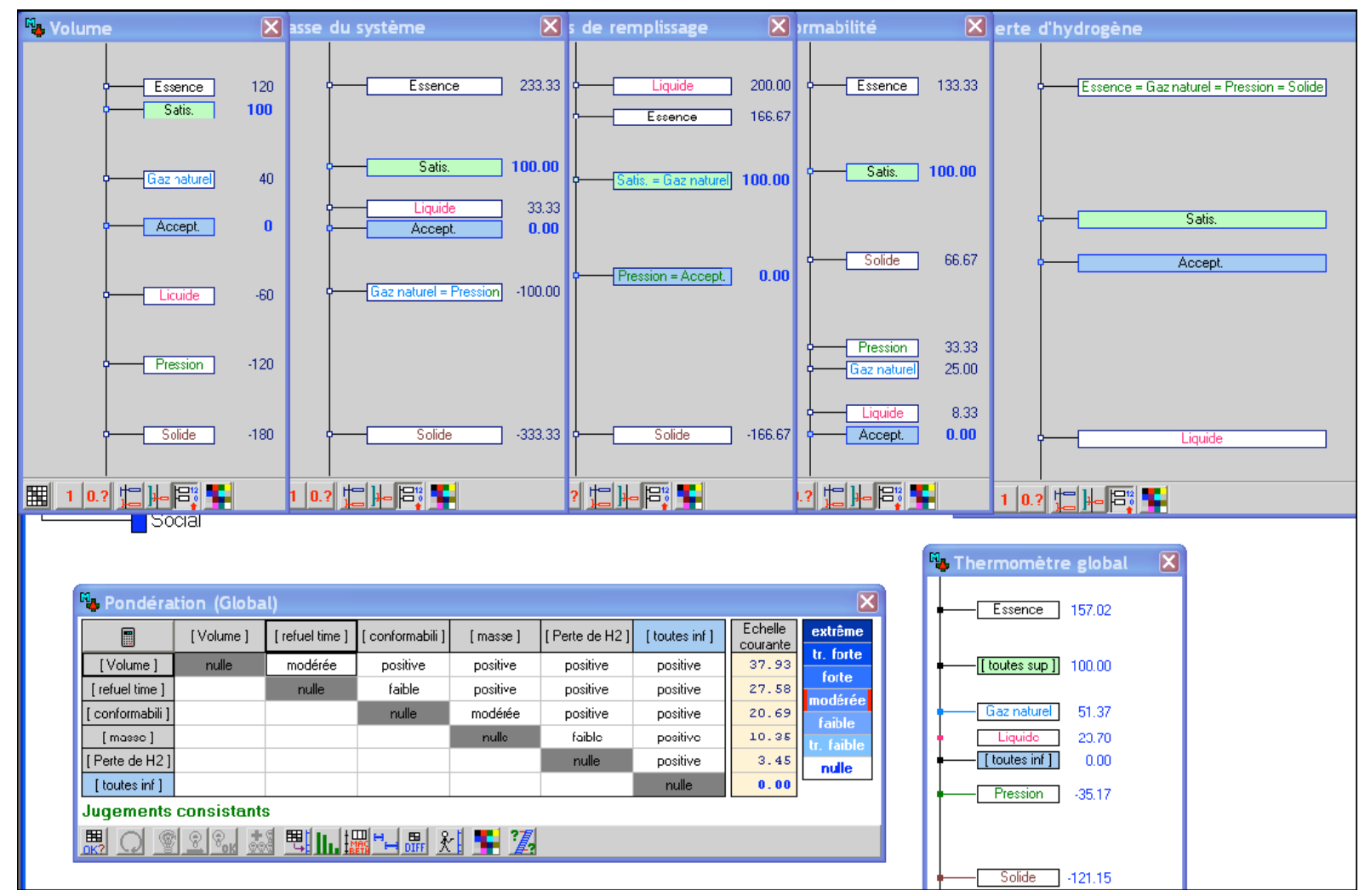

Figure 16 : MACBETH thermometers and judgement matrix for the weighting of the criteria obtained from Expert 1.




Figure 17 : MACBETH thermometers and judgement matrix for the weighting of the criteria obtained from Expert 2.

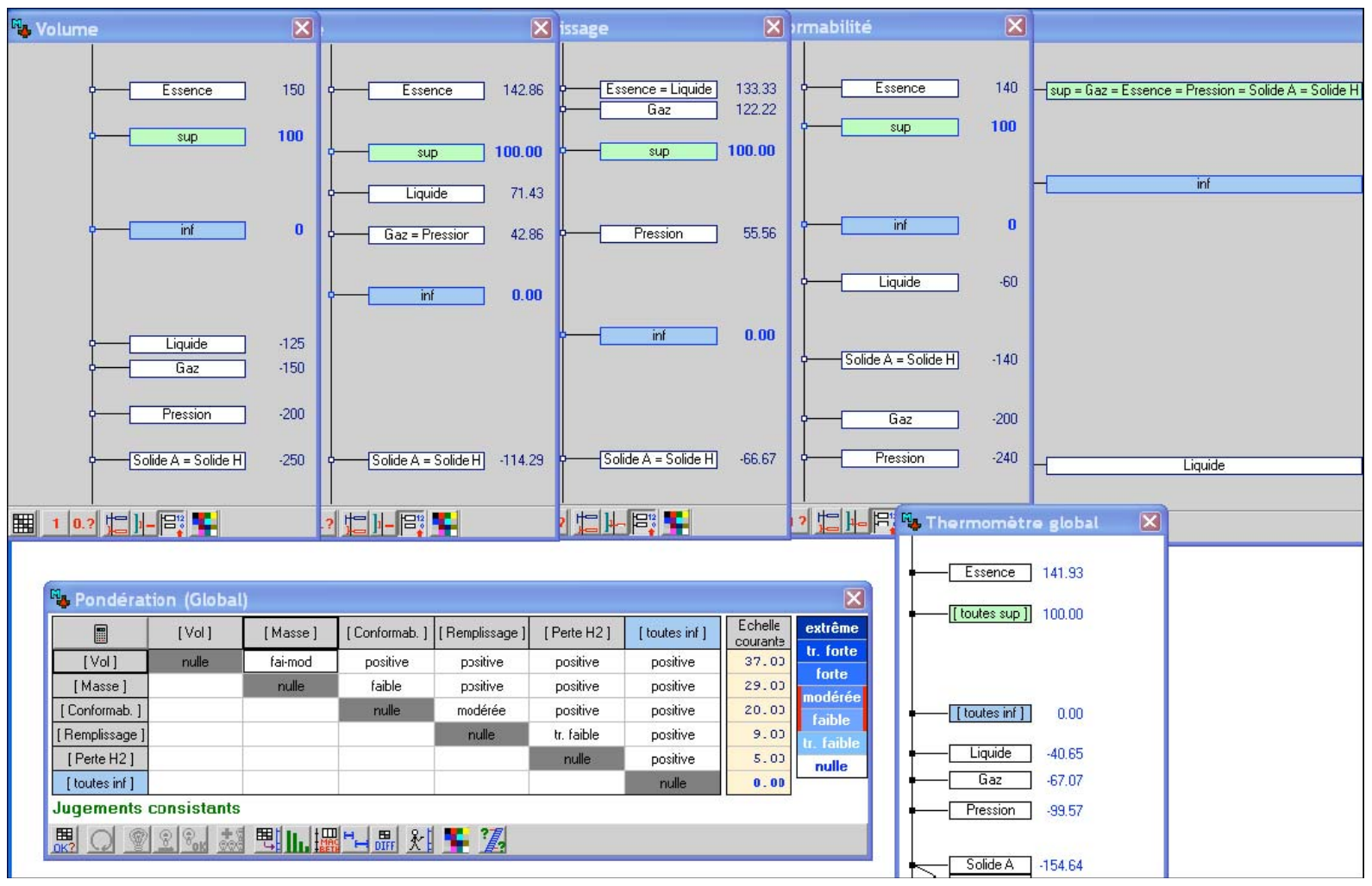

Figure 18 : MACBETH thermometers and judgement matrix for the weighting of the criteria obtained from Expert 3.

The following table provides the aggregated values obtained at the end of the MACBETH process and for each one of the interviewed expert.

\begin{tabular}{|l|c|c|c|}
\cline { 2 - 4 } \multicolumn{1}{c|}{} & Expert 1 & Expert 2 & Expert 3 \\
\hline Rank 1 & $\mathrm{ESS}=157$ & $\mathrm{ESS}=140$ & $\mathrm{ESS}=142$ \\
\hline Rank 2 & $\mathrm{SAT}=100$ & $\mathrm{SAT}=100$ & $\mathrm{SAT}=100$ \\
\hline Rank 3 & $\mathrm{GAZ}=51$ & $\mathrm{LIQ}=32$ & $\mathrm{ACC}=0$ \\
\hline Rank 4 & $\mathrm{LIQ}=24$ & $\mathrm{GAZ}=23$ & $\mathrm{LIQ}=-40$ \\
\hline Rank 5 & $\mathrm{ACC}=0$ & $\mathrm{SOL} \mathrm{BT}=6$ & $\mathrm{GAZ}=-67$ \\
\hline Rank 6 & $\mathrm{PRE}=-35$ & $\mathrm{PRE}=4$ & $\mathrm{PRE}=-99$ \\
\hline Rank 7 & $\mathrm{SOL}=-121$ & $\mathrm{ACC}=0$ & $\mathrm{SOL}=-154$ \\
\hline Rank 8 & & $\mathrm{SOL} \mathrm{A}=-20$ & \\
\hline
\end{tabular}

Table 13 : Summary of the aggregated values obtained at the end of the MACBETH process, according to the judgements of the interviewed experts.

\section{Evaluation profiles:}

The following figures are showing the evaluation profiles that have been obtained for each storage technology, according to the judgement of the interviewed experts. These profiles are providing a global vision of the strong and weak points of the technologies.

Liquid hydrogen storage: 


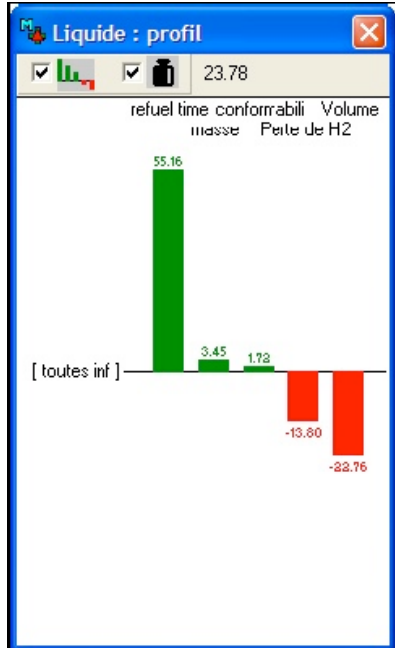

Expert 1

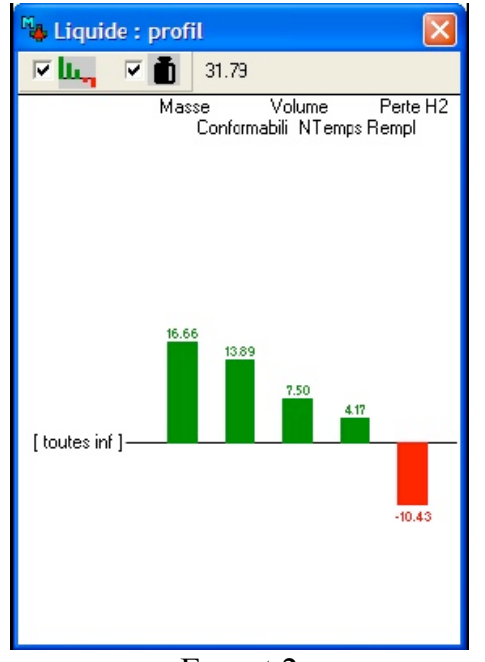

Expert 2

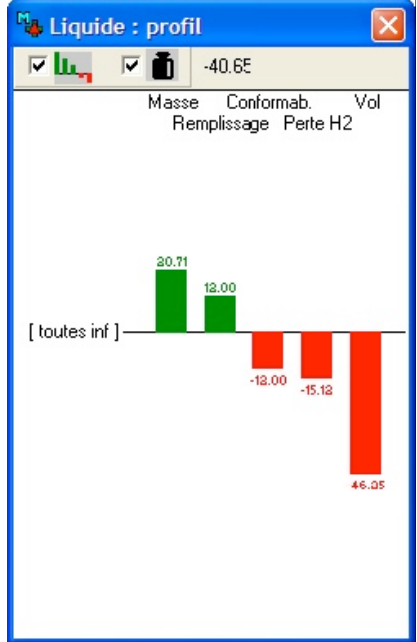

Expert 3

Compressed hydrogen storage:

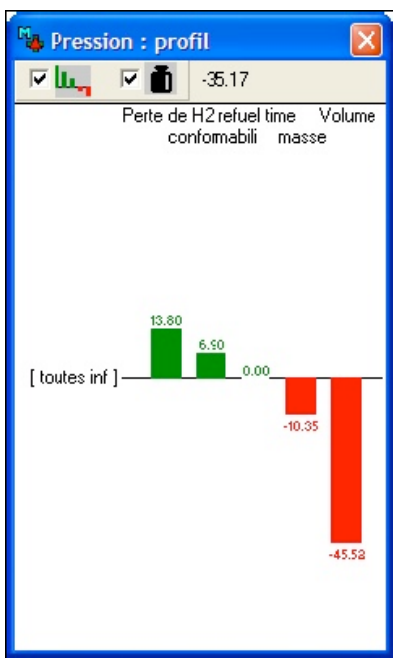

Expert 1

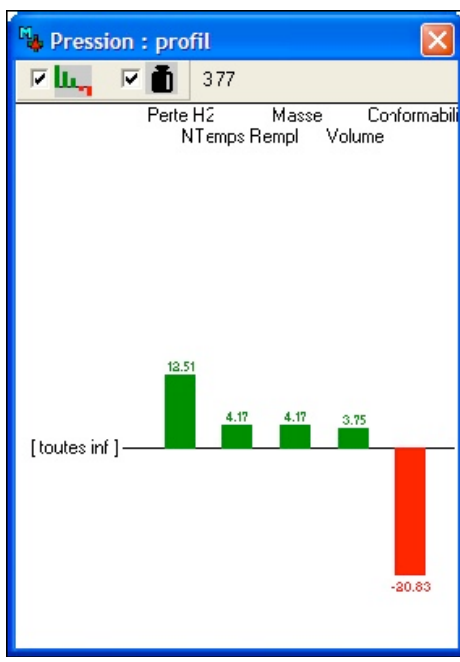

Expert 2

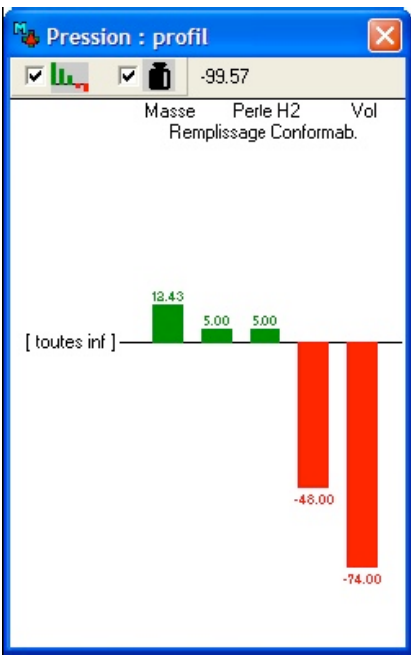

Expert 3

Solid storage:

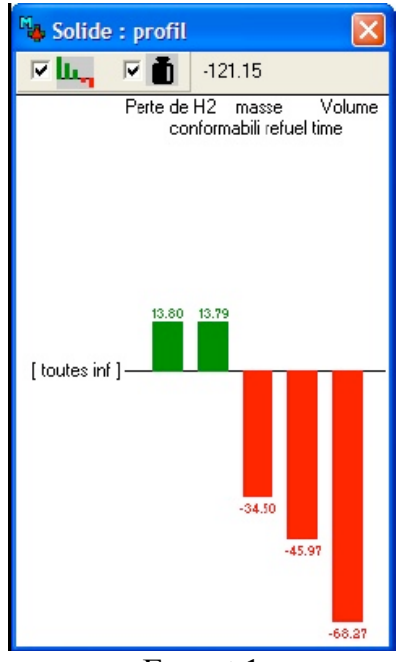

Expert 1

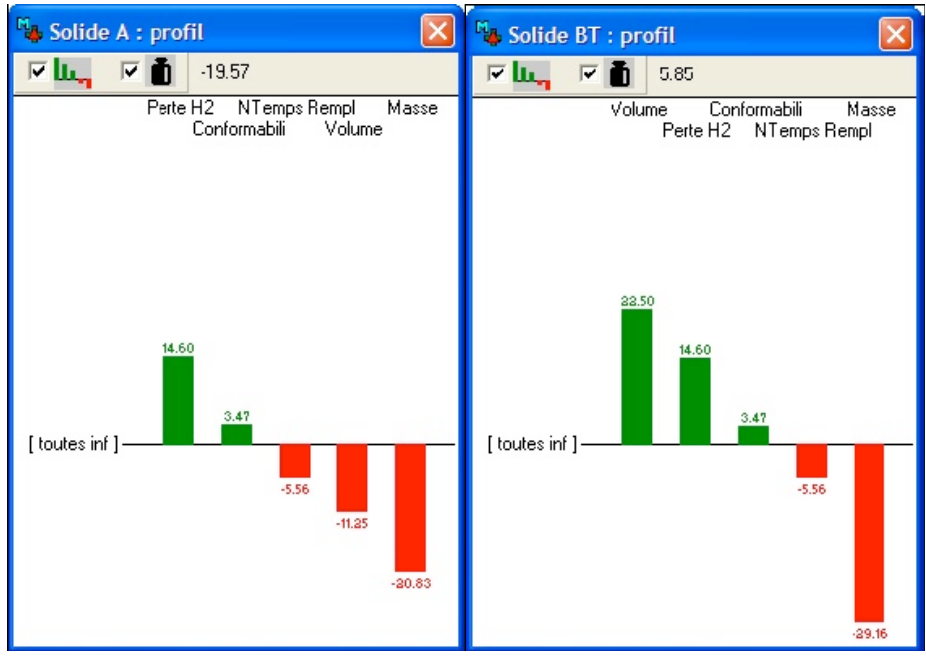

Expert 2

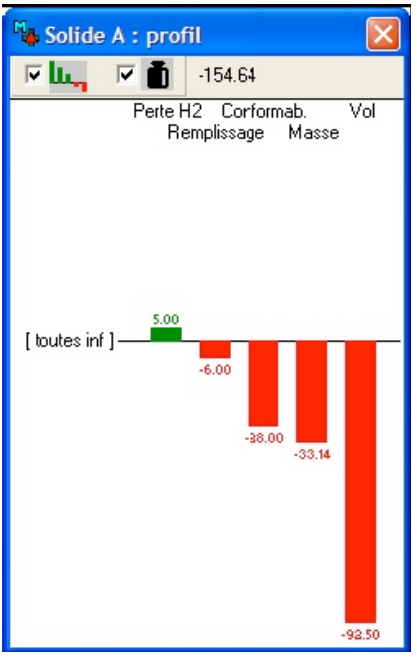

Expert 3 